\title{
O CLÁSSICO EM VIEIRA
}

Heitor Victor Narciso de Oliveira* (UERJ)

RESUMO: Os estudos sobre a literatura do século XVII, e especificamente sobre Antônio Vieira, são sempre muito férteis quando se deseja abordar a retórica ou mesmo a oratória. É inevitável, contudo, que tais estudos esbarrem nos clássicos que em muitos momentos fazem parte do arsenal argumentativo que será usado. Aqui pretendo, portanto, fazer breve apresentação do sermão de Vieira com base na leitura de Hansen e analisar o uso de autores do mundo clássico como parte do seu repertório argumentativo.

PALAVRAS-CHAVE: Vieira; Sermão; Clássico

\section{THE CLASSIC IN VIEIRA}

\begin{abstract}
Studies on 17th century literature, and specifically on Antônio Vieira, are always very fertile when it comes to approach rhetoric or even oratory. It is inevitable, however, that such studies will run into the classics that are often part of the argumentative arsenal that will be used. Here, therefore, I intend to make a brief presentation of Vieira's sermon based on Hansen's reading and analyze the use of authors from the classical world as part of his argumentative repertoire.
\end{abstract}

KEYWORDS: Vieira; Sermon; Classic

\section{Introdução}


A literatura e a cultura clássica deixaram marcas indiscutíveis no Ocidente. A força dessa cultura advém, claro, de uma dominação política, mas não só. O esforço intelectual de gregos e romanos foi fundamental para a construção de uma identidade europeia, se é que se pode falar em identidade ${ }^{1}$, mas acima de tudo foram fundamentais para a construção de uma tradição escrita que desembarcou com força total nas Américas. A Igreja Católica foi sem dúvidas o melhor veículo de disseminação dessa tradição no ocidente, espalhando, dentre outras formas, por meio da Companhia de Jesus uma cultura que tinha por hábito o registro escrito de suas diversas manifestações discursivas. O cristianismo e a cultura clássica possuem, portanto, um laço indelével se não na maneira de conceber o transcendente, certamente na maneira de expressar sua visão. É a retórica clássica e a oratória clássica que estarão nas bases intelectuais da Igreja.

É, contudo, no contexto da Contrarreforma que tal influência se fará muito marcante. As ferramentas clássicas de argumentação e lógica serão as principais "armas" das bases intelectuais da Igreja e é precisamente no Concílio de Trento que os sacerdotes católicos receberam maior liberdade para valorizar e reinterpretar os oradores romanos e os filósofos gregos. Não que isso seja realmente uma novidade, tendo em vista as tradições patrística e escolástica, entretanto a erudição que será valorizada no século XVII criará uma relação direta e natural entre o discurso do cristianismo católico e suas raízes clássicas.

Um dos maiores nomes de período, o Pe. Antônio Vieira nos deixa entender que compreendeu perfeitamente essa simbiose e em seus sermões podemos encontrar não poucas referências aos clássicos, de Aristóteles - já reconhecido pelos pares intelectuais - a Manílio e sua abordagem literária da astrologia. Vieira nos permite além de tudo, seguindo aquela já sugerida herança do registro escrito da tradição clássica, acessar parcialmente seus sermões por os ter publicado e assim nos dar uma ideia de uma das mais poderosas expressões orais de seu século. $\mathrm{O}$ que pretendo nesse breve trabalho é exatamente compreender de que maneiras diferentes os clássicos aparecem nos sermões de Vieira e em que medida eles são úteis para a construção da sua retórica, que, mesmo em forma, encontra sua gênese nos oradores do mundo antigo. A pergunta aqui não é SE aparecem os clássicos na sermonística de Vieira, mas COMO aparecem tais referências.

\footnotetext{
${ }^{1}$ A existência de um éthos europeu que encontra sua gênese na cultura clássica greco-romana é muitas vezes questionado precisamente pela diversidade de culturas que se formam na Europa e a grande participação de povos germânicos nessa formação. Há também grupos que negam tal identidade, como os Pré-rafaelitas ingleses, só a cargo de exemplo.

*Mestrando em Teoria da Literatura e Literatura Comparada - UERJ. Orientadora: Dra Fernanda Lemos de Lima.
} 
Seguirei um percurso simples e didático, pois principiarei por uma breve compreensão da forma e da estrutura do sermão de Antônio Vieira. Para isso recorrerei a um texto, também introdutório, de Adolfo Hansen, que me ajudará a perceber traços mais superficiais da obra de Vieira. Logo em seguida tentarei expor que mesmo nesse formato já se encontra, em certa medida, a referência ao clássico, falarei de como é autorizado ao sermonista a recorrência ao "juízo" de autoridades do mundo antigo para embasar sua retórica. Por fim trataremos em vias de fato das referências e para isso trarei breve análise de tais aparições em três sermões de Antônio Vieira: Sermão da Quarta-feira de Cinza em Roma, Sermão de Santo Antônio aos Peixes e Sermão de Nossa Senhora do Ó.

\section{Hansen e Vieira}

O primeiro passo a ser dado para compreender o uso de autores clássicos nos sermões de Antônio Vieira está na compreensão mínima da estrutura de seu texto. Sua obra será melhor compreendida se levantarmos os elementos fundamentais acerca de contexto e estilo, sua retórica e suas motivações. A aparição do texto clássico é um elemento que não deve ser visto, nem de longe, como o mais relevante. Acredito, entretanto, que reconhecer o motivo, a maneira e a importância das citações podem fortalecer a relevância dos estudos clássicos e seus impactos para a sociedade moderna.

Como suporte para uma breve abordagem do texto de Antônio Vieira escolhi recorrer à organização metódica de João Adolfo Hansen ${ }^{2}$. A realização do sermão de Vieira é esmiuçada de maneira didática e assim esse caminho cumpre bem o meu objetivo de apenas abordar de forma introdutória o autor para depois expor sua recorrência aos clássicos. O foco estará, portanto, nos elementos de maior relevância nessa primeira parte do trabalho e, por razões de síntese, não abordarei pormenores de obras específicas.

A compreensão de Vieira, portanto, começa pela necessária separação entre seu texto falado e seu texto escrito, somente assim se alcança a adequada leitura histórica. É preciso lembrar que mesmo que para ocasiões em que foram proferidos oralmente, os sermões escritos pelo autor passam por uma revisão, visando se adequar ao leitor, solitário, em condição diferente da do ouvinte que se coloca presente à própria expressão de Vieira. É impossível saber até que ponto existe fidelidade por parte do autor sobre seus próprios sermões quando da revisão

\footnotetext{
${ }^{2}$ HANSEN, João Adolfo. Maria ou a Eternidade do Tempo, in: VIEIRA, Antônio. Obra Completa de Pe. Antônio Vieira. Tomo II, Volume VII, Sermões de Nossa Senhora. Lisboa: Círculo de Leitores, 2014.
} 
para a publicação, afinal a informação importante acerca desse assunto é que o próprio autor trabalha seus textos para a publicação. Sobre o ponto central da diferença entre texto falado e escrito, Hansen nos alerta: "no tempo de António Vieira, o sermão era um discurso falado; hoje, é um texto lido. A sociedade de Vieira está extinta e o presente da leitura do sermão é o tempo de outra história, a nossa." 3

Um ponto óbvio, mas que não se pode prescindir em uma abordagem introdutória sobre Vieira é a sua compreensão do transcendente como inquestionável. Vieira parte sempre do pressuposto da existência de um Criador e não só, mas também uma espécie de organizador da natureza e do tempo. Tal menção é relevante, pois grande parte da argumentação do autor nos sermões está nas relações entre o Criador e a obra, como se esta, de alguma forma, espelhasse Aquele. Sobre isso Hansen afirma:

\begin{abstract}
"Todas as práticas de Vieira se fundamentam na ideia cristã de que a natureza e o tempo têm um Criador, [...] supõe que a substância espiritual da sua alma é participada pela luz natural do Verbo eterno, onde seu intelecto acha o fundamento das ideias como 'verbo interior' [...] o sentido providencial das concordâncias que estabelece entre eles está substancialmente figurado em coisas empíricas (in factis) e em palavras das Escrituras (in verbis)."
\end{abstract}

Vieira, ainda segundo Hansen, interpreta as palavras de Deus segundo três níveis de sentido espiritual: o alegórico, o tropológico e o anagógico. Alegórico "quando as coisas da escritura se referem a Cristo ou à Igreja. [...] O sentido tropológico refere-se aos costumes [...] Quanto ao anagógico, significa a condução das que se vivem no tempo para o futuro e a Eternidade." ${ }^{\circ}$ É possível, portanto, entender que há uma relação temporal em sua leitura de Deus, na qual há sempre um sentido voltado para o passado, o alegórico; para o presente, o tropológico; e para o futuro, o anagógico. Reconhecer esses aspectos da interpretação das Escrituras por parte do autor no permite entender melhor o seu próprio texto.

Chegando finalmente à retórica de Vieira encontramos o que será o elemento central do presente trabalho, pois é no recurso a autoridades que encontraremos um ponto de partida para a argumentação. É preciso compreender, entretanto, que por si só o sermão já é revestido de

\footnotetext{
${ }^{3}$ Ibidem. P. 9.

${ }^{4}$ Ibidem. P. 10

${ }^{5}$ Ibidem. P. 10 e 11.
} 
uma elevação moral em razão de seu emissor. "O eu que fala no sermão é o de um tipo discreto - prudente, grave, engenhoso, agudo - institucionalmente autorizado a falar sobre os fins últimos do homem." Esse "tipo discreto" é além de tudo dotado de virtudes que somadas à base nas autoridades constrói um discurso que fundamenta a adequação moral. Tais virtudes são o engenho e o juízo, este é a capacidade de ponderar sobre questões éticas e políticas que se pudessem se colocar nos sermões e aquele a capacidade de organizar com habilidade a retórica. É preciso, portanto, não deixar de relevar o valor desse chamado juízo para a retórica de Vieira, pois a ele voltarei algumas vezes mais a frente.

Como entrarei detidamente nas referências a autoridades clássicas mais tarde, é possível avançar no método retórico de Vieira em direção à sua composição da fala. O autor busca dar solidez ao que argumenta por meio de experiências coletivas e constituindo o ouvinte por meio de paixões, ou seja, são postas para o destinatário imagens baseadas no cotidiano para afetá-lo e convencê-lo do que se pretende. Essas imagens muitas vezes permitem variações que enfatizam sua relação com o objeto tratado na retórica de Antônio Vieira, sempre respeitando, contudo, os seguintes princípios: "falando a superiores, não é jocoso; a iguais, não é descortês; a inferiores, não é orgulhoso."7

Analisando o sermão propriamente dito, encontramos de pronto uma construção com base nas três operações retóricas: a invenção, a disposição e a elocução. Há sempre uma referência que figurará como ideia central da qual se depreendem questões especificativas. Quem? Quê? Com quê? Com quem? Como? Quando? Onde? Por quê? Como isso a matéria que figurará no ponto central da argumentação pode ser já determinada, assim como os caminhos retóricos por que percorrerá. Caminhos esses que serão trilhados com base nos três gêneros oratórios: deliberativo, aconselhamento sobre a conduta futura em certas ocasiões; judicial, que trata de episódios ou eventos que já aconteceram sob uma perspectiva de justo ou injusto; e, por fim, epidítico, que trata de eventos presentes de maneira crítica e valorativa.

Com isso temos ainda uma separação temporal a motivar o sermão, que pode sempre se relacionar ao passado, ao presente e ao futuro. Vieira adota a postura de um conselheiro moral do social e do espírito. Interpreta a matéria de que trata, segundo Hansen, sob o preceito retórico do ductus,

"a condução do discurso, que relaciona a matéria sacra com questões do presente em que prega como consilium [...] O conselho evidencia o seu providencialismo, postulação de que na história se lê o desígnio da

\footnotetext{
${ }^{6}$ Ibidem. P. 11.

${ }^{7}$ Ibidem. P. 12.
} 
Vontade divina; e o seu profetismo, prognóstico do futuro revelado especularmente em coisas, homens e eventos do passado e do seu presente." 8

Antônio Vieira constrói assim uma série de relações entre passado, presente e futuro; entre eventos, pessoas e profetas. Caminha por seu percurso retórico engendrando analogias que figuram muitas vezes como base da argumentação.

Partindo para a organização estrutural do texto de Antônio Vieira encontraremos, ainda segundo análise de Hansen, o seguinte esquema: exórdio, "introdução que prepara o ânimo do destinatário com a captação de benevolência em que é apresentado o tema" ${ }^{9}$, dividido em proposição e divisão; narração, exposição da matéria e "a confirmação ou a refutação dos argumentos expostos."10; e epílogo, no qual Vieira costuma retomar o que foi proposto no exórdio a apresentar a conclusão a que se chegou, permitindo-se, além disso, a peroração, "apelo patético feito ao destinatário para o comover."11

A estrutura sintática de Vieira também busca respeitar o princípio da simetria aplicado em outras esferas do sermão. Há aqui a busca pelo espelhamento das formulações que parte de um número específico de membros que sobem e descem na mesma proporção: prótase e apódose. Vieira é claro, elegante e muito agudo, característica esta última relacionada à capacidade de aproximação adequada e contundente de coisas e conceitos distantes. Acerca dessa agudeza Hansen nos alerta:

\footnotetext{
"tais relações metafóricas [...] eram substancialmente motivadas, evidenciando concordâncias metafísicas entre coisas, conceitos e signos. Também recorre a figuras patéticas, associadas aos movimentos intelectuais da sua alma, aplicando-as persuasivamente ao estilo da narração."12
}

Assim se apresentam as metáforas dos sermões de Vieira, nunca apenas uma comparação ocasional, mas sempre uma relação metafísica que corrobora com a concepção de simetria entre criador/criatura. Todo efeito é reflexo da Palavra de Deus.

\section{Aparições do Clássico}

\footnotetext{
${ }^{8}$ Ibidem. P. 13.

${ }^{9}$ Ibidem. P. 14.

${ }^{10}$ Ibidem. P. 14.

${ }^{11}$ Ibidem. P. 14.

12 Ibidem. P. 15.
} 
O uso dos clássicos como parte integrante da construção do sermão pode ser visto como anterior a um mero uso de autoridade na argumentação. Não se deve esquecer que a formação de um sacerdote no século XVII incorporava em grande parte a tradição erudita classicista. Os tratados de oratória, lógica e retórica eram a base teórica por trás da formação de Antônio Vieira. Torna-se imprescindível, portanto, começarmos analisando brevemente como a estrutura da sermonística de Vieira apresentada anteriormente recebe influência da tradição clássica.

Adolfo Hansen cita ${ }^{13}$ como referências da tradição retórica para Vieira autores como: Aristóteles, Cícero, Quintiliano e Teofrasto. Expõe ainda que a construção de Vieira seria composta como etopeia, ou seja, o suporte encontrado na tradição clássica não se limita à forma de produção, mas também no caráter e no valor dos indivíduos nos quais irá suportar sua argumentação. Como um texto de natureza formadora, portanto, o modelo importa para a estrutura e ainda como figura a ser seguida enquanto exemplo moral. Cada nome que aparece, portanto, na retórica de Vieira precisa se justificar intelectualmente e moralmente para compor a sua constante relação entre forma e conteúdo.

Aristóteles, em seu conjunto de obras denominado Organon, influencia grandemente a produção de Vieira. O autor ordena o seu discurso com as técnicas do conceito engenhoso, o ornato dialético, segundo Hansen,

"por meio das dez categorias definidas por Aristóteles [...] substância, quantidade, qualidade, lugar, posição, relação, paixão, ação, tempo, hábito - dialeticamente faz definições da matéria, figurando retoricamente como metáforas e alegorias os conceitos obtidos; analisando-as, inventa dialeticamente outros conceitos, que volta a figurar retoricamente como novas metáforas e alegorias; de novo as analisa dialeticamente, definindo novos conceitos, que figura retoricamente com novas metáforas e alegorias"14

Um fator importante a se observar acerca do uso dos clássicos por Antônio Vieira é que a própria Igreja Católica autorizou e, de certa forma, incentivou tal uso a partir do Concílio de Trento, dentre outras coisas por conta da sindérese, a consciência que guia juízo e o conduz à correção moral do discurso. Ao reconhecer o valor da retórica clássica e que o falar de modo

\footnotetext{
13 Ibidem. P. 11.

${ }^{14}$ Ibidem. P. 14
} 
justo já encerra em si a orientação divina, a Igreja abre possibilidades infindas para o uso dos clássicos e para a inserção de certo caráter erudito da sermonística. "A partir do Concílio de Trento, as perspectivas oratórias católicas retomam textos gregos e latinos de retórica, afirmando que o juízo do orador é iluminado pela luz natural da graça inata" ${ }^{15}$, sendo assim, os pensadores da antiguidade surgem como autoridades que darão ainda mais robustez ao que exprime o sermão, pois “aconselha e orienta a significação do que diz como eficácia didática, prazer engenhoso e comoção persuasiva" $"$.

Começo aqui a identificar as aparições dos clássicos nos sermões propriamente ditos e nada melhor do que fazê-lo inicialmente pelo Sermão de Quarta-feira de Cinza em Roma ${ }^{17}$. Vieira começa por estabelecer uma hierarquização interessante acerca de homens, deuses e Deus. Ele entende que um fator decisivo para entender a singularidade do Deus cristão é a sua não transitoriedade de estado e com isso ele resgata o deuses antigos como base do seu argumento, fazendo assim com que fique claro que o uso de referências clássicas está precisamente da maneira como decidido pelo Concílio de Trento, resgatando apenas o juízo dos oradores, não seus elementos míticos.

Eu bem sei que também há deuses da terra, e que esta terra onde estamos foi a pátria comum de todos os deuses, ou próprios, ou estrangeiros. Aqueles deuses eram de diversos metais; estes são de barro, ou cru ou mal cozido, mas deuses. Deuses na grandeza, deuses na majestade, deuses no poder, deuses na adoração, e também deuses no nome: Ego dixi, dii estis. Mas se houver, que pode haver, se houver algum destes deuses que cuide ou diga: Ego sum qui sum, olhe primeiro o que foi e o que há de ser. Se foi Deus, e há de ser Deus, é Deus: eu o creio e o adoro; mas se não foi Deus, nem há de ser Deus, se foi pó, e há de ser pó, faça mais caso da sua sepultura que da sua divindade. ${ }^{18}$

Vieira explica assim a transitoriedade de todos os seres que não Deus, tal relação será a base de seu argumento de que o homem na verdade é pó, claro, abrindo sua abordagem acerca da quarta-feira de cinza. Ainda nesse mesmo trecho, o sermão apresenta logo abaixo menção aos grandes nomes no mundo antigo, de Roma, e faz então nova referência para garantir que mesmo os grandes nomes da História são passíveis do mesmo fenômeno, de serem pó. Com

\footnotetext{
15 Ibidem. P. 19.

16 Ibidem.

${ }^{17}$ VIEIRA, Antônio. Os Sermões de Padre Antônio Vieira. Versão Digital: Montecristo Editora, 2012.

${ }^{18}$ Ibidem. Posição 834.
} 
isso Vieira nos permite reconhecer a importância, para o público a que se dedica nesse sermão e para a própria produção, da cultura clássica.

Passa Santo Agostinho da sua África à nossa Roma, e pergunta assim: Ubi sunt quos ambiebant civium potentatus? Ubi insuperabiles imperatores? Ubi exercituum duces? Ubi satrapae et tyranni?. Onde estão os cônsules romanos? Onde estão aqueles imperadores e capitães famosos, que desde o Capitólio mandavam o mundo? Que se fez dos Césares e dos Pompeus, dos Mários e dos Silas, dos Cipiões e dos Emílios? Os Augustos, os Cláudios, os Tibérios, os Vespasianos, os Titos, os Trajanos, que é deles? Nunc omnia pulvis: tudo pó; Nunc omnia favillae: tudo cinza; Nunc in poucis versibus eorum memoria est: não resta de todos eles outra memória, mais que os poucos versos das suas sepulturas. ${ }^{19}$

Vieira avança no sermão tratando da efemeridade da vida humana e da importância de se reconhecer que todos somos iguais perante Deus e que devemos nos conformar com este estado. A certa altura podemos notar nova menção aos clássicos, mas dessa vez não apenas uma lembrança com o intento de deixar mais vivo o argumento, mas uma citação direta, transparecendo o quanto um autor clássico, retomando a ideia do juízo, pode sim figurar como autoridade em um argumento. A autoridade evocada é Sêneca: "Morimur ut mortales, vivimus ut imortales: morreremos como mortais que somos, e vivemos como se fôramos imortais. Assim o dizia Sêneca gentio à Roma gentia." 20

Avanço nessa análise com um trecho subsequente de Antônio Vieira em seu jogo retórico. O autor tão logo faz a citação direta e já nos traz uma retorsão, adiantando um contraargumento que para o presente trabalho se faz de grande importância. Ele defende o uso de um autor antigo e essa defesa é esclarecedora, pois clarifica bem o que se entendeu por respeito ao juízo, ao menos na visão apresentada por Vieira. "Vós a isto dizeis que Sêneca era um estoico. E não é mais ser cristão que ser estoico? Sêneca não conhecia a imortalidade da alma; o mais a que chegou foi a duvidá-la, e contudo entendia isto." Vieira defende, portanto, Sêneca, em sua compreensão, mesmo não sendo cristão, ajudando-nos assim a compreender um pouco melhor como poderiam ser lidos os clássicos no século XVII.

Ainda acerca do Sermão de Quarta-feira de Cinza encontramos nova citação dos clássicos que pode ajudar a compreender um outro aspecto, a possibilidade de reinterpretação,

\footnotetext{
${ }^{19}$ Ibidem. Posição 955.

${ }^{20}$ Ibidem. Posição 1063. A citação a Sêneca é de: De Consolat ad Marciam.
} 
no caso cristão, de tais autores antigos. Logo o seu valor é reconhecido, mas não sem antes a necessidade de leitura crítica de sua retórica. Vieira, ainda tratando do transitório da vida, cita Aristóteles, mas acrescenta logo em seguida sua sentença sobre a compreensão do mesmo. "Aristóteles disse que entre todas as coisas terríveis, a mais terrível é a morte. Disse bem mas não entendeu o que disse. Não é terrível a morte pela vida que acaba, senão pela eternidade que começa. Não é terrível a porta por onde se sai; a terrível é a porta por onde se entra." ${ }^{21}$ Em uma leitura mais severa, podemos concluir certa leviandade do sermonista em simplesmente reinterpretar o filósofo grego, pois ele aplica uma análise com base no pensamento cristão, que por razões históricas não se adequaria a Aristóteles, mas não podemos nos esquecer de que para Vieira há uma razão divina por traz da razão humana e as relações são sempre aplicáveis aos planos natural e divino - como apresentado por Hansen e resgatado acima neste trabalho. É com base nesta certeza de que há um fio condutor unindo o logos humano ao divino, precisamente aí reside a afirmação de Vieira e sua pertinência para o seu sermão.

Parto agora para os demais sermões, para que as referências aos clássicos, que são férteis na obra de Vieira, fiquem mais sólidas. A intenção até aqui foi apresentar como essas referências podem aparecer de maneiras diversas e com objetivos distintos. Tratarei de mais alguns casos para que fique clara a sua aparição em diversos sermões. Começo, portanto, com o Sermão de Santo Antônio aos Peixes ${ }^{22}$, no qual Vieira estabelece uma alegoria contínua, que perpassa todo o texto, que usa os peixes para se referir aos tipos de homens.

Novamente a citação é a Aristóteles e novamente para dar base a um argumento que será central na retórica do sermão. Vieira afirma que a virtude do peixe, comparando-se a outros animais, está justamente na sua distância, em diversos aspectos, do homem. Imaginando não serem os peixes animais passíveis de serem domesticados ou que se assemelhem em comportamento, de alguma forma, aos homens. Claro que mesmo essa pretensa distância é alegórica, mas a maneira como ele irá usar Aristóteles para se ajustar à sua posição é exemplar.

Falando dos peixes Aristóteles, diz que só eles entre todos os animais se não domam, nem domesticam. Dos animais terrestres o cão é tão doméstico, o cavalo tão sujeito, o boi tão serviçal, o bugio tão amigo, ou tão lisonjeiro, e até os leões, e os tigres com arte, e benefícios se amansam. Dos animais do ar afora aquelas aves, que se criam, e vivem conosco, o papagaio nos fala, o rouxinol nos canta, o açor nos ajuda, e nos creia; e até as grandes aves de rapina encolhendo as unhas reconhecem as mãos de quem recebem o sustento. Os peixes pelo

\footnotetext{
${ }^{21}$ Ibidem. Posição 1078.

22 VIEIRA, Antônio. Obra Completa Padre de Pe. Antônio Vieira. Tomo II, Vol. X, Sermões Hagiográficos I. Lisboa: Círculo de Leitores, 2014.
} 
contrário lá se vivem nos seus mares, e rios, lá se mergulham nos seus pegos, lá se escondem nas suas grutas, e não há nenhum tão grande, que se fiem do homem, nem tão pequeno, que não fujam dele. ${ }^{23}$

Assim, mesmo que de maneira incipiente, as referências vão aparecendo e sempre fomentam um caráter de autoridade aos sermões de Antônio Vieira. No Sermão de Nossa Senhora do $\hat{O}^{24}$, a referência é feita ao poeta e astrólogo Marco Manílio, mostrando que não só na filosofia se pode encontrar a substância para a construção da retórica. O uso de Manílio se dá, contudo, não como citação de autoridade, mas para a construção de uma das analogias realizadas acerca da Virgem Maria, neste caso Vieira a compara com o Signo de Virgem.

Manílio no livro quarto da sua Astronomia diz uma coisa admirável, e é que os que nascem debaixo do Signo de Virgem recebem desta influência tal graça no escrever, que uma letra sua contém uma palavra: Hic et scriptor erit, feliz cui littera verbum est. Eu não direi o fundamento que teve Manílio para sair com este axioma, nem os outros astrônomos o comentam facilmente. Mas o certo é que Cristo nasceu debaixo do Signo da Virgem; o certo é que Cristo nesse mesmo mistério diz de Si que é um $O$ : e o certo é que esta letra, e este $O$ contém a primavera, e maior palavra, que é o Verbo Eterno: Cui littera Verbum est. ${ }^{, 25}$

Vale notar que Vieira faz questão de afirmar que não sabe de onde Manílio tirou sua afirmação e que mesmo seus pares não o saberiam dizer, no entanto, como aqui a razão não é o fundamento principal, mas sim a composição e o embasamento da alegoria, a conclusão a que se chega, afirma o autor do sermão, é que realmente importa.

Há também no mesmo sermão mais duas citações a Sêneca no intuito de dar fundamentação a uma alegoria, na primeira aparição, e a uma proposição moral, ao final do sermão. Inicialmente a referência é feita quando se trata da relação entre as ondas das águas e o formato do Ó. O uso de Sêneca dessa vez não é mera menção alegórica, mas surge para aprofundar ainda mais a analogia, pois partindo do autor clássico Vieira estende sua lógica também à luz e ao som. Farei aqui a citação completa do argumento para que fique clara a importância da referência para a retórica no sermão.

\footnotetext{
${ }^{23}$ Ibidem. P. 141 e 142.

${ }^{24}$ VIEIRA, Antônio. Obra Completa de Pe. Antônio Vieira. Tomo II, Volume VII, Sermões de Nossa Senhora. Lisboa: Círculo de Leitores, 2014.

${ }^{25}$ Ibidem. P. 381.
} 
Se acaso, ou de indústria lançastes uma pedra ao mar sereno, e quieto, ao primeiro toque da água vistes alguma perturbação nela; mas tanto que essa perturbação se sossegou, e a pedra ficou dentro do mar, no mesmo ponto se formou nele um círculo perfeito, e logo outro círculo maior, e após este outro, e outros, todos com a mesma proporção sucessiva, e todos mais estendidos sempre, e de mais dilatada esfera. Este efeito maravilhoso celebra muito Sêneca no primeiro livro das suas Questões Naturais, e dele aprenderam os filósofos o modo com que a voz, e a luz se multiplicam, e dilatam por todo o ar. Mas se a natureza na multiplicação, e extensão destes círculos teve outro intento mais alto, sem dúvida foi para nos declarar com a propriedade desta comparação o modo com que os OO dos desejos da Senhora ao passo com que se multiplicavam, juntamente se estendiam.

De forma um pouco diferente, Sêneca é novamente evocado no Sermão de Nossa Senhora do Ó em sua censura a Alexandre o Grande, mostrando assim o ponto de Vieira acerca do desejo sem limites. Há aqui, portanto, dupla citação à cultura clássica, pois resgatar uma das figuras mais icônicas da História clássica, e sua insaciável busca por mais e mais seja lá o que for que Alexandre procurasse, é de grande impacto para o seu argumento. Sêneca aparece, contudo, como a marca do autor possuidor do juízo que deve ser valorizado nos clássicos. O sermão encerra assim o seu ponto com grande impacto para o leitor/ouvinte instruído de Vieira que entende suas referências.

Condenando Sêneca a ambição monstruosa de Alexandre, disse com profunda sentença: Inventus est qui aliquid concupisceret post omnia. Basta que se achou no mundo um homem, que depois de ter tudo, ainda desejou mais alguma coisa? O tudo que possuía, e dominava Alexandre, era nada; só Deus verdadeiramente é tudo. ${ }^{26}$

Sêneca é citado também de maneira direta aqui, tal qual Ovídio, em outra parte do sermão, o que nos mostra que mesmo o texto poético dos clássicos, encontra espaço na sermonística de Vieira. E não só. Será resgatado também um mito que se notabilizou no ocidente, o mito de Narciso, fechando assim essa minha breve abordagem de como autores clássicos - além da própria cultura clássica - podem aparecer de maneira fértil nos sermões de Vieira. A retórica agora conduz o sermão para a explicação do desejo intrínseco aos OO de Nossa Senhora, um desejo pelo que está dentro de si e que não se pode ver, consequentemente,

\footnotetext{
${ }^{26}$ Ibidem. P. 395. O texto em latim pode ser traduzido como o seguinte: "Achou-se aquele que desejaria ainda alguma coisa depois de tudo ter."
} 
por completo. Vieira diz: “O objeto da vista, para se poder ver, há de ser presente; mas se está pegado, e unido à mesma potência, é como se estivesse ausente: há de se estar apartado dos olhos, para se pode ver." ${ }^{27}$ Para embasar a afirmação e, por conseguinte, o argumento, evocase Ovídio - de maneira direta - e o mito de Narciso.

É a queixa de Narciso, com verdadeira razão em história fabulosa: Quod cupio mercum est; inopem me copia fecit: 'O que desejo, tenho-o em mim; e porque o tenho em mim, careço do que tenho'. Pois que remédio? Votum in amante novum: 'O remédio é um desejo novo', qual nunca desejou quem amasse. E que desejo é este? Vellem quod amamus abesse: 'Desejar que o que amo se ausente, e se aparte de mim'. Tal era o desejo da Senhora, e tal a razão seu desejo. Carecia do mesmo bem, que tinha, porque $\mathrm{O}$ tinha dentro de si. Por isso suspirava, e desejava com ânsia vê-Lo já fora: e esta era a causa dos seus OO: Quis mihi det te fretrem meum, ut inveniam te foris $[\ldots]^{28}$

\section{Conclusão}

É, dentre outros elementos, a recorrência aos clássicos em seus sermões que Vieira deixa transparecer a necessidade de um público minimamente instruído. A quem Vieira falava não se pode, contudo, precisar, mas certamente ao publicar seus sermões, o autor nos deixa uma intenção mais duradoura acerca de trabalho de orador, legar à posteridade sua agudeza, seu engenho e seu juízo acerca das coisas do passado, do presente e do futuro. O sermão de Vieira acessa a cultura clássica de diversas maneiras e foi precisamente isso que pretendi mostrar nesse breve estudo. Seria possível passarmos mais inúmeras páginas recortando exemplos de tais referências, mas nem faria muito sentido fazê-lo, pois se perderia a motivação introdutória deste tipo de trabalho.

Podemos entender, ainda que de maneira superficial, que a base da retórica clássica está presente em Antônio Vieira a começar pela forma do texto, na maneira como se organiza a argumentação. Há o elemento inovador, sem dúvidas, principalmente quando Vieira estabelece as razões divinas entre os seres e as coisas, mas há um uso importante de nomes como Aristóteles e Sêneca. Ao mencionar esses dois nomes entendemos que a referência pode se

\footnotetext{
${ }^{27}$ Ibidem. P. 390.

${ }^{28}$ Ibidem. A citação a Ovídio é: Metamorfoses, 3, 466. O último trecho em latim pode ser traduzido como o seguinte: "Quem te entregará a mim, irmão meu, para que eu saia ao teu encontro?"
} 
apropriar de uma postulação moral ou intelectual, e não apenas um uso de autoridade especialista ou eminente como o fazemos hoje.

A citação dos clássicos é realizada em Vieira tanto direta quanto indiretamente, a um texto filosófico ou literário, mas sempre será apenas suporte para o argumento principal que se tenta defender. É preciso entender que a citação aos clássicos não ganha voz de verdade absoluta, muito pelo contrário, pode ser criticável para a construção de um posicionamento ainda mais sólido, ou de melhor leitura da autores antigos. As referências são sempre passíveis de serem analisadas e Vieira chega mesmo a afirmar compreensões "equivocas" que os citados autores por vezes realizam.

A importância maior desse trabalho reside não em ser definitivo no que diz respeito a como Antônio Vieira usa os clássicos em seus sermões, mas acima de tudo em fomentar a reflexão de como os clássicos assim o são exatamente por seu poder de atualização, de se manterem presentes em nossa cultura até os dias de hoje. Vieira hoje possui mesmo status, o de se fazer presente, de se atualizar e ainda poder dizer algo de valor para o leitor contemporâneo. Contudo, para que significações não se percam, entender as relações entre literaturas - e culturas - pode tornar tal valor ainda mais enriquecedor, seja para a compreensão contextual, seja por enriquecimento de nossas leituras diacrônicas desses que ganharam a alcunha de clássicos.

\section{Referências}

HANSEN, João Adolfo. Maria ou a Eternidade do Tempo, in: VIEIRA, Antônio. Obra Completa de Pe. Antônio Vieira. Tomo II, Volume VII, Sermões de Nossa Senhora. Lisboa: Círculo de Leitores, 2014.

VIEIRA, Antônio. Os Sermões de Padre Antônio Vieira. Versão Digital: Montecristo Editora, 2012.

VIEIRA, Antônio. Obra Completa Padre de Pe. Antônio Vieira. Tomo II, Vol. X, Sermões Hagiográficos I. Lisboa: Círculo de Leitores, 2014.

VIEIRA, Antônio. Obra Completa de Pe. Antônio Vieira. Tomo II, Volume VII, Sermões de Nossa Senhora. Lisboa: Círculo de Leitores, 2014. 